\title{
A case report of blunt liver trauma in times of COVID-19 pandemic
}

\author{
Vlad Braga*, Iulian Slavu*, Adrian Tulin**, Bogdan Socea***, Lucian Alecu** \\ *Clinical Emergency Hospital, Bucharest, Romania \\ **"Prof. Dr. Agrippa Ionescu" Clinical Emergency Hospital, Bucharest, Romania \\ ***"Sf. Pantelimon" Emergency Hospital, Bucharest, Romania
}

Correspondence to: Slavu Iulian, General Surgery Clinic, Clinical Emergency Hospital, Bucharest, 8 Calea Floreasca Street, District 1, Bucharest, Romania, Mobile phone: +40752 596 675, E-mail: iulian.slavu@yahoo.com

\begin{abstract}
The liver is one of the most affected organs in abdominal trauma mostly because of its considerable dimensions, the fragility of the liver parenchyma.

We present the case of a 29 -year-old patient who sustained an abdominal trauma after an accidental fall from a $3 \mathrm{~m}$ height. The patient tested positive at RT-PCR for SARS-CoV-2 at admission, without any symptoms of viral infection. The emergency CT scan revealed a blunt liver trauma with an expanding hematoma (grade III). The patient was initially hemodynamically stable but shortly after admission became unstable and required surgical treatment that initially consisted of damage control and liver packing. Reintervention was decided 36 hours later, after reevaluation unpacking and hepatorrhaphy were done. The postoperative evolution was uneventful. The case indicated the importance of continuous monitoring of the traumatic patient. In liver trauma, hemodynamic instability guarantees an emergency laparotomy. The time of operations in trauma patients with SARS-CoV-2 must be reduced to the maximum both as an objective of damage control and also to minimize the risk of contagion.
\end{abstract}

Keywords: liver trauma, Covid-19, surgery

\section{Introduction}

The liver is one of the most affected organs in abdominal trauma mainly due to its large size, the fragility of the parenchyma and Glisson's capsule, significant vascularity, and location in relation to the anterior abdominal wall, below the coastal rim [1].

The most important steps in the therapeutic approach to liver trauma are rapid diagnosis and determination of the degree of injury [2]. The therapeutic strategy has undergone significant changes in recent decades, nowadays nonoperative being frequently used in liver trauma for hemodynamically stable patients [3]. Although nonoperative management has advanced significantly, the treatment should be tailored primarily to the physiological conditions of the continuously monitored patient [4]. The decisive factor for the surgical intervention is hemodynamic stability.

The higher the degree of the injury, the greater the risk of the patient to become 
hemodynamically unstable, which will require emergency surgery. Surgical intervention and damage control is focused on obtaining hemodynamic stability rather than the immediate and complete treatment of injuries [5]. Liver packing is one of the techniques used in cases of abdominal trauma with massive bleeding in order to obtain compression on the parenchyma and reduce the time of surgery [6].

The severity of liver trauma is classified in grades and morbidity and mortality vary according to the grade (Table 1). Also, this classification is used as a treatment guide (Table 1).

\begin{tabular}{|c|c|c|}
\hline Grade & Lesion type & Lesion description \\
\hline \multirow[t]{2}{*}{ I } & Hematoma & Subcapsular $<10 \%$ surface \\
\hline & Laceration & Capsular tear $<1 \mathrm{~cm}$ parenchyma depth \\
\hline \multirow[t]{2}{*}{ II } & Hematoma & Subcapsular $10-50 \%$ surface area; intraparenchymal $<10 \mathrm{~cm}$ diameter \\
\hline & Laceration & $1-3 \mathrm{~cm}$ parenchymal depth; <10 cm in length \\
\hline \multirow[t]{2}{*}{ III } & Hematoma & $\begin{array}{l}\text { Subcapsular }>50 \% \text { surface area or expanding; ruptured subcapsular or parenchymal } \\
\text { hematoma; intraparenchymal hematoma }>10 \mathrm{~cm}\end{array}$ \\
\hline & Laceration & $>3 \mathrm{~cm}$ parenchymal depth \\
\hline IV & Laceration & Parenchymal rupture $25-75 \%$ of hepatic lobe or $1-3$ Couinaud segments \\
\hline \multirow[t]{2}{*}{ V } & Laceration & Parenchymal rupture $>75 \%$ or $>3$ Couinaud segments \\
\hline & Vascular & Juxtahepatic veins injuries (suprahepatic veins or retrohepatic vena cava) \\
\hline $\mathrm{VI}$ & Vascular & Hepatic avulsion \\
\hline
\end{tabular}

\section{Case report}

A 29-year-old patient presented to the emergency room with intense pain in the upper abdomen that occurred after an accidental fall from approximately 3 meters, 36 hours prior to examination. At the clinical examination, the patient had normally colored skin, no trauma marks, a mobile abdomen with breathing movements, intense pain spontaneously and at palpation in the right hypochondrium. The patient was tachycardic with a pulse of $105 \mathrm{bpm}$ and slightly increased blood pressure with values of $145 / 86 \mathrm{mmHg}$. Serological tests and complete blood count were performed and identified hemoglobin values within normal limits, leukocytosis $(15,000 / \mathrm{mmc})$, hyperglycemia (121 mg/ dl), and an increase in transaminase values of 2-3 N (AST - $120 \mathrm{U} / \mathrm{L}, \mathrm{ALT}$ - $113 \mathrm{U} / \mathrm{IT}$ ). During monitoring in the emergency room, samples were collected for RT-PCR testing for SARSCoV-2.

Due to the discrepancy between the clinical examination and the biochemical values, an emergency computer tomography (CT) with intravenous contrast substance was performed, which showed a subcapsular hematoma in the right liver lobe with a maximum thickness of $6 \mathrm{~cm}$ with multiple foci of active bleeding and dimensional growth on the late sequence and presence of hemoperitoneum with a maximum thickness of $1 \mathrm{~cm}$ (grade III hepatic lesion) (Fig. 1-3). No post-traumatic or infectious lesions were visible in the lungs (Fig. 1-3).

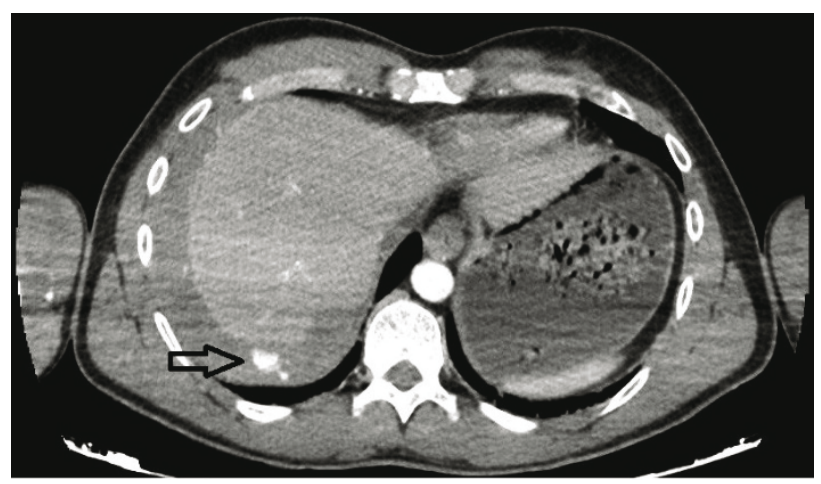

Fig. 1 Active bleeding inside hematoma (black arrow) 


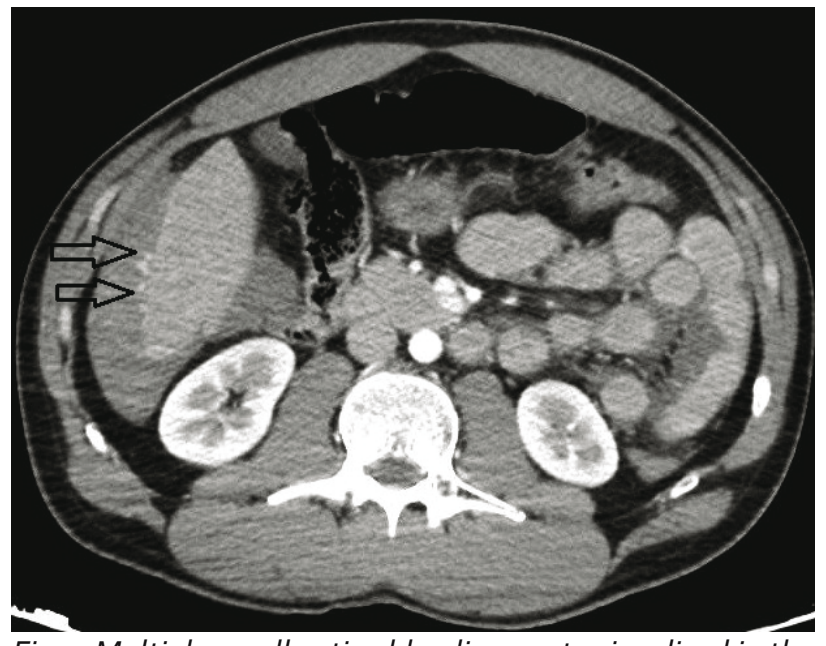

Fig. 2 Multiple small active bleeding spots visualized in the $\mathrm{VII}^{\text {th }}$ Couinaud segment (black arrows)

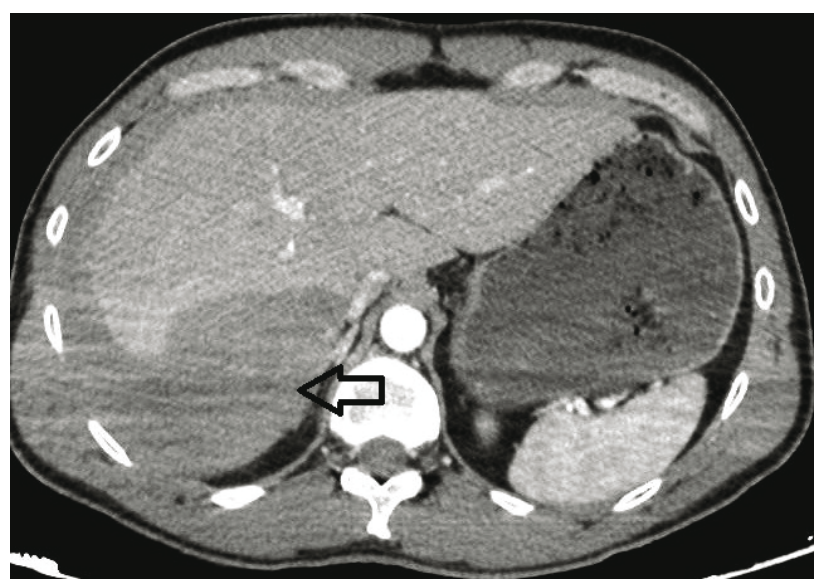

Fig. 3 Subcapsular hematoma in the right hepatic lobe (black arrow)

After 60 minutes from the computer tomography, the patient's condition worsened. He became hemodynamically unstable (blood pressure dropped to $75 / 50$ $\mathrm{mmHg}$ ) and an emergency laparotomy was decided. Intraoperatively, massive hemoperitoneum and subcapsular hematoma were identified, which occupied the entire right hepatic lobe. After lavage and drainage of the hemoperitoneum (approximately 2000 $\mathrm{ml}$ ) and evacuation of the hematoma, superficial diffuse hepatic bleeding was identified in the $\mathrm{V}^{\text {th }}$ and $\mathrm{VII}^{\text {th }}$ Couinaud segments. Due to the hemodynamic instability and diffuse bleeding a liver packing was performed as a damage control measure. Postoperatively, the patient was transferred to the intensive care unit. The evolution was marked by the externalization of $2000 \mathrm{ml}$ of blood on the drainage tubes within the first 24 hours. Diagnostic and therapeutic angiography was performed and did not identify areas of active bleeding in the territory of the common hepatic artery and the superior mesenteric artery. Reintervention to remove the liver packing was decided after 36 hours postoperatively. Also, hepatorrhaphy was performed where active bleeding foci were identified. The postoperative evolution was uneventful. The patient was discharged on the $8^{\text {th }}$ postoperative day in good general condition with no viral impregnation symptoms or signs.

\section{Discussion}

Computer tomography with intravenous contrast substance is considered the gold standard in trauma diagnosis. It can be performed only on a hemodynamically stable patient or responder to fluid resuscitation [8].

Understanding the classification of hepatic injury is of utmost importance in choosing the treatment option. The main four classification systems are represented by the Abbreviated Injury Score (AIS), the American Association for Surgery of Trauma (AAST) grading system, the Injury Severity Score, and the World Society of Emergency Surgery (WSES) grading system $[7,9,10]$. The most widely used is the AAST grading system and it utilizes only CT imaging and does not take into account the clinical state of the patient.

Recent studies have shown an 80-100\% success rate of nonoperative management in liver trauma [11]. However, the conversion rate to surgery is $10 \%$ in initially hemodynamically stable patients [11]. Nonoperative management (NOM) must be considered for hemodynamically stable patients with minor (AAST I-II), moderate (AAST III-IV), and severe (AAST V-VI) lesions in 
the absence of other abdominal injuries that would require surgery [12]. For these patients, NOM is considered the treatment of choice.

The WSES 2020 guidelines recommend that surgical intervention in liver trauma must be considered in case of a hemodynamically unstable patient, with other abdominal organ injury or evisceration. The main objective is to arrest the hemorrhage, control the bile leaks, and allow intensive resuscitation as soon as possible [13].

Perihepatic packing is a viable option when there is an uncontrollable hemorrhage in a hemodynamically unstable patient. This technique is recommended also when coagulopathy, bilobar liver injury, or large nonexpanding hematoma and capsular avulsion are encountered [14].

One important aspect of the perihepatic packing is that this maneuver will not arrest arterial hemorrhages. To be effective for this type of lesion, the artery must be ligated or sutured prior to perihepatic packing. For accurate liver packing, the surgeon must commence with a Pringle maneuver and a dissection of the perihepatic ligaments [4].

The optimal timing for the extraction of the hepatic packing is hemodynamic stability of the patient and remission of the coagulopathy, acidosis, and hypothermia [15]. In most cases, a second laparotomy is needed at 24-36 hours. The use of perihepatic packing can lead to postoperative complications such as respiratory distress or abdominal compartment syndrome $[16,17]$.

The current COVID-19 pandemic has both direct and indirect effects on the evolution of trauma patients [18]. The approach to both nonoperative and surgical treatment has changed, with De Mauro arguing that surgical decisions must be made based on the medical algorithm but also taking precautions to minimize the risk of contagion [19]. Clement et al. identified SARS-CoV-2 infection as an independent risk factor for mortality and a positive diagnosis at admission (by RT-PCR) significantly increases the rate of postoperative complications [20].

\section{Conclusions}

The present case reiterates the importance of continuous monitoring of the trauma patient. In liver trauma, hemodynamic instability requests an emergency laparotomy. The time of surgery in trauma patients with SARS-CoV-2 must be reduced to the maximum both as an objective of damage control but also to minimize the risk of contagion.

\section{Conflict of Interest}

The authors state no conflict of interest.

\section{Informed Consent and Human and Animal Rights statements}

An informed consent has been obtained from the individual included in this study.

\section{Authorization for the use of human subjects}

Ethical approval: The research related to human use complies with all the relevant national regulations, institutional policies, is in accordance with the tenets of the Helsinki Declaration, and has been approved by the institutional review board of the Clinical Emergency Hospital, Bucharest, Romania.

\section{Acknowledgements}

None.

\section{Sources of Funding}

No funding was required for this study.

\section{Disclosures}

None. 


\section{References}

1. Ahmed N, Vernick JJ. Management of liver trauma in adults Journal of Emergencies, Trauma and Shock, vol 4, 2011, Wolters Kluwer - Medknow Publications, 114-9.

2. Letoublon $C$, Amariutei A, Taton N, Lacaze L, Abba J, Risse O, Arvieux C. Management of blunt hepatic trauma. J. Visc. Surg. 2016; 153:33-43.

3. Ibrahim AH, Osman AJ, Alarfaj MA, Alzamil AM, Abahussain MA, Alghamdi $\mathrm{H}$. Case report: Evisceration of abdomen after blunt trauma. Int. J. Surg. Case Rep. 2020; 72: 207-11.

4. Doklestić $K$, Stefanović $B$, Gregorić $P$, Ivančević $N$, Lončar $Z$, Jovanović $B$, Bumbaširević $V$, Jeremić $V$, Vujadinović ST, Stefanović B, Milić N, Karamarković A. Surgical management of AAST grades III-V hepatic trauma by Damage control surgery with perihepatic packing and Definitive hepatic repair-single centre experience. World J. Emerg. Surg. 2015; 10:1-8.

5. Petrowsky $H$, Raeder S, Zuercher L, Platz A, Simmen HP, Puhan MA, Keel MJ, Clavien PA. A quarter century experience in liver trauma: A plea for early computed tomography and conservative management for all hemodynamically stable patients. World J. Surg. 2012; 36:247-54.

6. Caruso DM, Battistella FD, Owings JT, Lee SL, Samaco RC. Perihepatic packing of major liver injuries: Complications and mortality. Arch. Surg. 1999; 134:95863.

7. Moore EE, Cogbill TH, Jurkovich GJ, Shackford SR, Malangoni MA, Champion HR. Organ injury scaling: Spleen and liver (1994 revision). J. Trauma - Inj. Infect. Crit. Care. 1995; 38:323-4.

8. Yoon W, Yong YJ, Jae KK, Jeong JS, Hyo SL, Sang SS, Jung CK, Seong WJ, Jin GP, Heoung KK. CT in blunt liver trauma. Radiographics. 2005; 25;87-104.

9. Loftis $\mathrm{KL}$, Price J, Gillich PJ. Evolution of the Abbreviated Injury Scale: 1990-2015. Traffic Inj. Prev. 2018; 19:S109-13.

10. Javali RH, Krishnamoorthy, Patil A, Srinivasarangan $M$, Suraj, Sriharsha. Comparison of injury severity score, new injury severity score, revised trauma score and trauma and injury severity score for mortality prediction in elderly trauma patients. Indian J. Crit. Care Med. 2019; 23:73-7.

11. Fang J-F, Wong Y-C, Lin B-C, Hsu Y-P, Chen M-F. The CT Risk Factors for the Need of Operative Treatment in Initially Hemodynamically Stable Patients After Blunt Hepatic Trauma. J. Trauma Inj. Infect. Crit. Care. 2006; 61:547-54.

12. Azzam AZ, Gazal AH, Kassem MI, Souror MA. The role of non-operative management (NOM) in blunt hepatic trauma. Alexandria J. Med. 2013; 49:223-7.

13. Coccolini $F$, Coimbra R, Ordonez $C$, Kluger $Y$, Vega $F$, Moore EE, Biffl W, Peitzman A, Horer T, Abu-Zidan FM, Sartelli M, Fraga GP, Cicuttin E, Ansaloni L, Parra MW, Millán $M$, Deangelis $N$, Inaba K, Velmahos G, Maier R, Khokha V, Sakakushev B, Augustin G, Di Saverio S, Pikoulis E, Chirica M, Reva V, Leppaniemi A, Manchev V, Chiarugi $M$, Damaskos D, Weber D, Parry N,
Demetrashvili Z, Civil I, Napolitano L, Corbella D, Catena F, Bahouth $H$, Tolonen M, Fugazzola P, Serna JJ, Rodriguez F, Garciá AF, Gonzalez A, Pino LF, GuzmánRodríguez $M$, Pereira $B M$, Kirkpatrick $A$, Mefire $A C$, Tarasconi A, Chiara O, Gomes CA, Galante J, Bala M, Perfetti P, MacHado F, Romeo O, Salvetti F, Ghiadoni L, Forfori F, Malacarne P, Pini S, Pucciarelli M, Ceresoli M, Arvieux C, Khokha D, Spain DA, Isik A. Liver trauma: WSES 2020 guidelines. World J. Emerg. Surg. 2020; 15:35.

14. Paydar $S$, Mahmoodi $M$, Jamshidi $M$, Niakan $H_{\text {, }}$ Keshavarz M, Moeenvaziri N, Ghorbaninejad ME, Farrokhnia F, Izadi Fard F, Jaafari Z, Golshan Y, Abbasi H, Bolandparvaz S, Honarvar B. Perihepatic Packing versus Primary Surgical Repair in Patients with Blunt Liver Trauma; an 8-year Experience. Bull. Emerg. Trauma. 2014; 2: 103-9.

15. Nicol AJ, Hommes M, Primrose $R$, Navsaria $\mathrm{PH}$, Krige JEJ. Packing for control of hemorrhage in major liver trauma. World J. Surg. 2007; 31:569-74.

16. Sharp KW, Locicero RJ. Abdominal packing for surgically uncontrollable hemorrhage Annals of Surgery. vol. 215, 1992, Lippincott, Williams, and Wilkins, 467-75.

17. Scollay JM, Beard D, Smith R, McKeown D, Garden OJ, Parks R. Eleven years of liver trauma: The Scottish experience. World J. Surg. 2005; 29:744-9.

18. Coleman JR, Burlew CC, Platnick KB, Campion E, Pieracci F, Lawless R, Werner N, Coleman J, Hoehn M, Moore EE, Cohen MJ. Maintaining Trauma Care Access During the COVID-19 Pandemic: An Urban, Level-1 Trauma Center's Experience. Ann. Surg. 2020; 272:e5860.

19. De Mauro D, Rovere G, Smimmo A, Meschini C, Mocini F, Maccauro G, Falez F, Liuzza F, Ziranu A. COVID-19 pandemic: management of patients affected by SARSCoV-2 in Rome COVID Hospital 2 Trauma Centre and safety of our surgical team. Int. Orthop. 2020; 1-5.

20. Clement ND, Hall AJ, Makaram NS, Robinson PG, Patton RFL, Moran M, Macpherson GJ, Duckworth AD, Jenkins PJ. IMPACT-Restart: the influence of COVID-19 on postoperative mortality and risk factors associated with SARS-CoV-2 infection after orthopaedic and trauma surgery. Bone Joint J. 2020; 1-8. 